\title{
THE HISTORY OF THE ELECTRICAL AGTIVITY OF THE BRAIN AS A METHOD FOR LOCALIZING SENSORY FUNCTION
}

by

\author{
MARY A. B. BRAZIER
}

ThE history of the discovery of the electrical activity of the brain $4,5,6$ is part and parcel of the history of the localization of function in the brain, for its initial development had this as its specific goal. At the mid-eighteenth century, scientists seeking knowledge of the brain could look back on a history of their field that revealed a gradual evolution of anatomical knowledge about its structure, but only conjecture about its physiology.

A marked advance in understanding the physiology of the brain came when techniques were developed for ablating and stimulating parts of the central nervous system without the animal succumbing to the procedures. The surgery in the early attempts was frequently so drastic that results were rarely specific. For example, the experimental results of Willis that confirmed his belief in the cerebellum as a vital centre were probably due to his animals having succumbed to injuries near the fourth ventricle. Other early experimenters such as Duverney ${ }^{18}$ with his pigeons, and Chirac ${ }^{14}$ and Perrault ${ }^{44}$ with their dogs had to be satisfied with very brief durations of survival.

At the opening of the nineteenth century interest in localization of cerebral function had been widely stirred by the lectures of Franz Gall ${ }^{27}$ in Vienna. Unfortunately Gall's reputation as a phrenologist has overshadowed his more important work on the fibre tracts of the white matter of the brain, work which clarified the previously contradictory ideas as to the anatomy of the commissures and of the pyramidal decussation. But, while his contemporaries were concerning themselves with sites for motor functions, Gall was proposing localization of mental faculties and he may be regarded as a pioneer in emphasizing the importance of the grey matter for intellectual processes. It was when, with his pupil, Spurzheim ${ }^{28,}$ 29, he proceeded to assign separate 'organs' in the brain to the different mental faculties and to relate these to bumps on the skull that he began to be challenged. All the same, in spite of its bizarre concepts, phrenology had a surprisingly wide acceptance for a considerable period even among the medical profession. It was to the psychologists (although that term was not yet in use) that phrenology particularly appealed, for it was the first major consideration of mental characteristics as attributes of brain function.

One of the more prominent men to attack Gall's doctrines was Flourens, who made a sweeping rejection of all such ideas ${ }^{24}$ denying the brain any discretely localized action. But Flourens's monograph appeared some years after the deaths of Gall and Spurzheim, both of whom had built up comfortable 


\section{Mary A. B. Brazier}

careers out of their specialty. Flourens ${ }^{22,}{ }^{23}$ recognized three major functional regions of the brain (the cerebral hemispheres, the medulla and the cerebellum), but within these entities he envisaged their action as global and their roles as being sensory, vital and motor respectively. Concerning the cerebral hemispheres he said that animals that survive their removal 'lose perception, judgment, memory and will ... therefore the cerebral hemispheres are the sole site of perception and all intellectual abilities'. He did not hesitate to infer subjective qualities and faculties. In one of the more renowned of his experiments he had kept a pigeon alive after removal of its cerebral hemispheres. The bird was 'blind' and 'deaf' and appeared to be asleep, although it stirred when poked. Flourens went so far as to say that the bird lost its volition and 'even the faculty of dreaming'. He noted that it retained the sense of equilibrium and that its pupils still reacted to light. Others repeating Flourens's experiments were unconvinced, for their decerebrate pigeons could be startled by a loud noise and could avoid obstacles.

Since sudden death followed section of the medulla, Flourens concluded that here lay the essential mechanism for respiration and the maintenance of life. In this conclusion he had of course been anticipated by Legallois. ${ }^{37}$ Much of Flourens's fame as an experimentalist derived from his observation that extirpation of the cerebellum (in birds and mammals) caused loss of co-ordinated movement. Flourens, whose interest lay so deeply in the elucidation of the control of voluntary movement, was himself to suffer paralysis for a long period before his death.

In the I820s when Flourens was pursuing these experiments, many workers were 'mutilating' animals (to use Gall's phrase) and some jockeying for priority was inevitable. Most of Flourens's observations, particularly those on the cerebellum, had been anticipated by Rolando 15 at Sassari, whose treatise of 1809 (written in Italian and printed and illustrated by himself) was therefore republished in French in an abbreviated form in 1824 .

All the experiments so far related could give information only about motor function-there was no clue to the localization of sensory function in the brain and, of course, no clue to the function of speech, for extirpation experiments on animals could give no guide to the cortical representation of speech.

This had to come from clinical observation with studies at autopsy. Gall had placed language in the anterior lobes and the first clinical reports seemed to confirm this. In fact, the great surge of work aiming to establish localized centres in the human brain began with the speech centre. In his studies of encephalitis Bouillaud, ${ }^{3}$ a pupil of Magendie and later professor of medicine, had reasoned that the anterior lobes of the brain were necessary for speech and went on to observe that other focal lesions of the brain caused localized impairment of muscular movement. The cause of cerebral localization was taken up by his son-in-law, Auburtin, ${ }^{1}$ who predicted that a lesion would be found in the anterior lobes of an aphasic patient who was at that time in the hospital of Bicêtre under the surgeon Pierre Broca. ${ }^{7}$ Autopsy confirmed Auburtin's prediction, pinpointing the lesion in the left anterior lobe. The next aphasic patient on Broca's service was found at autopsy to have an even more discrete lesion-in 

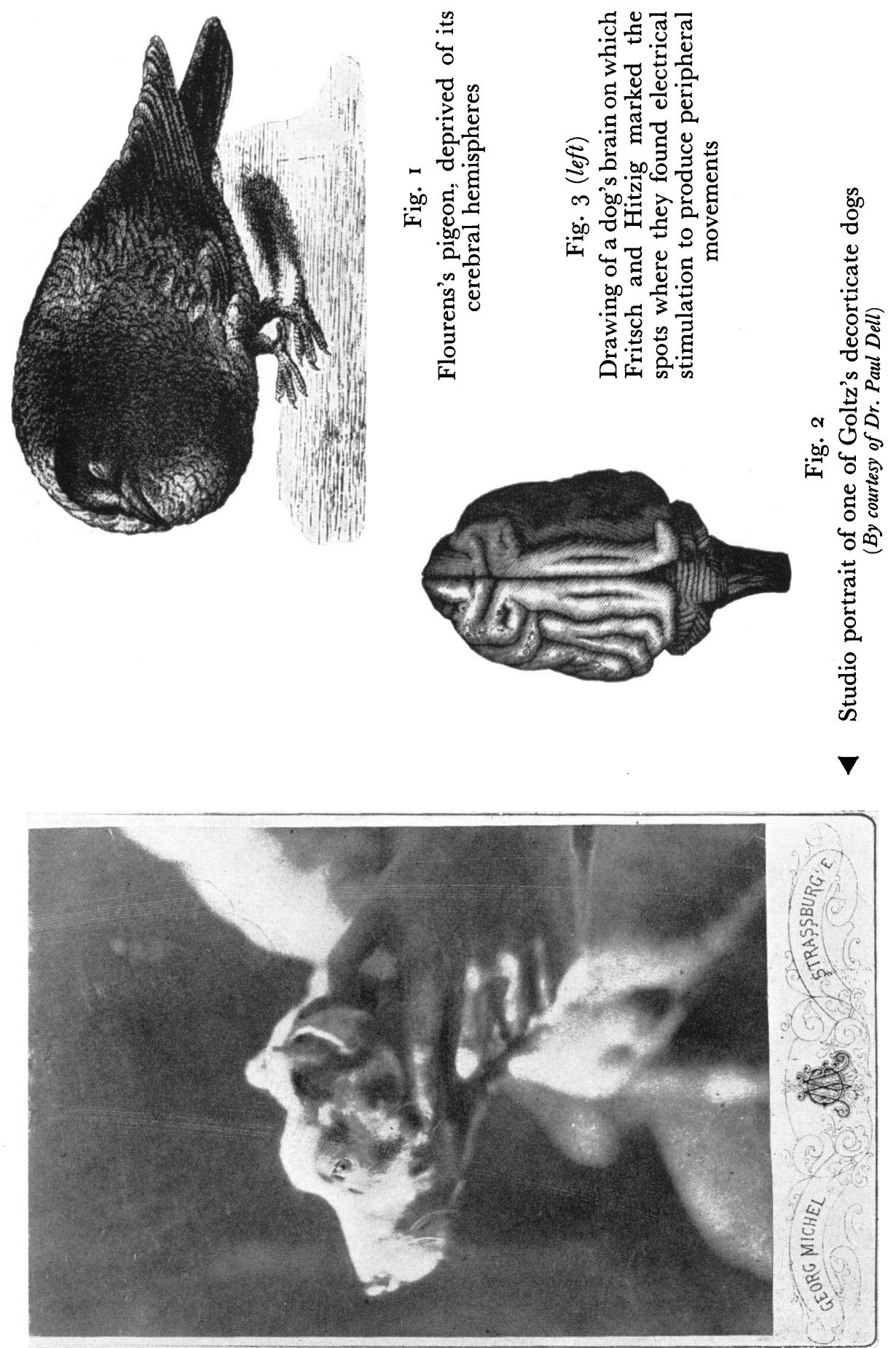

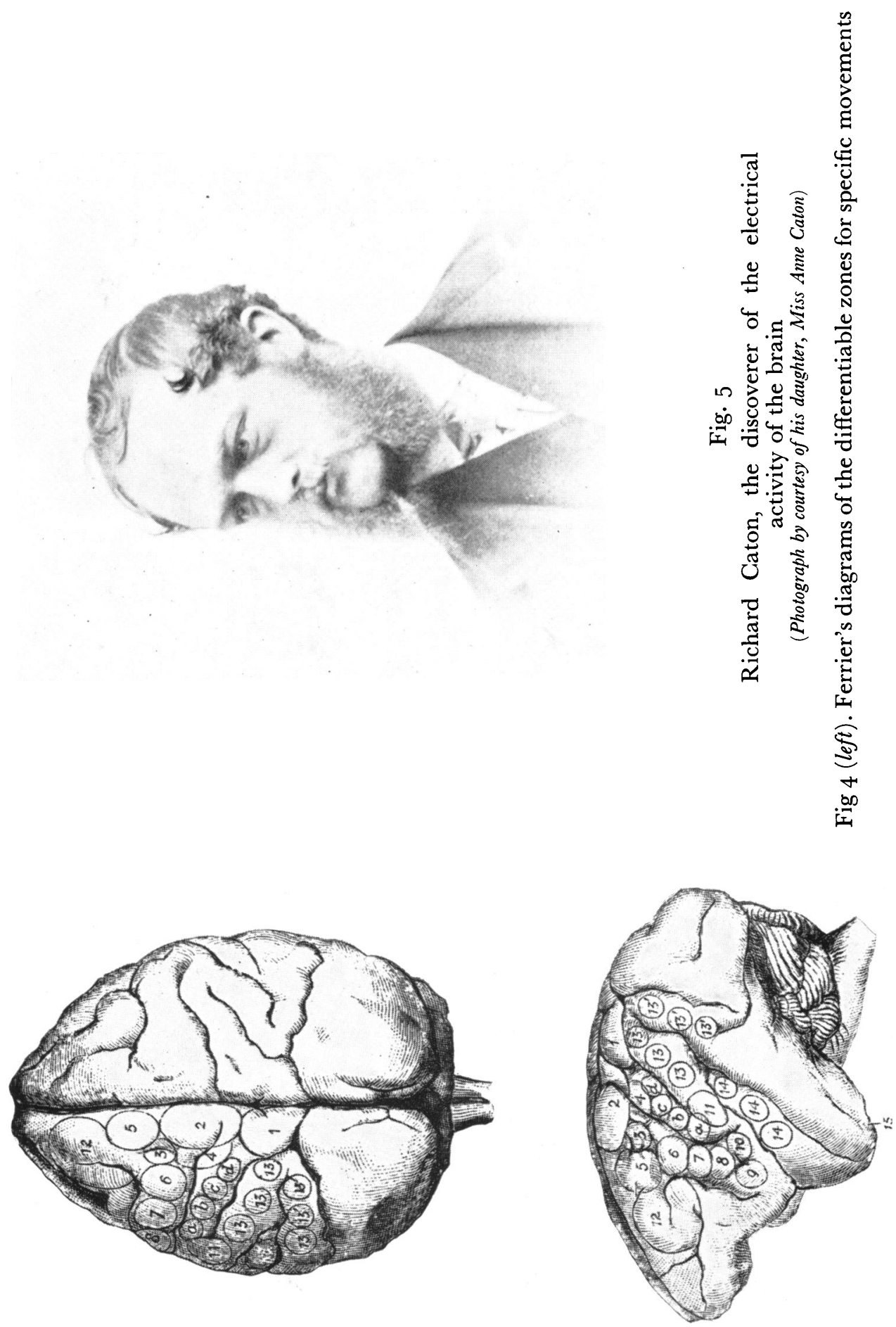


\section{The History of the Electrical Activity of the Brain}

what is known to this day as Broca's area. The name of Auburtin has been forgotten, as has Broca's term 'aphemia' for aphasia.

However, for the physiologists, the technique of purposeful ablation of specific parts of the brain seemed a more promising route to localization of brain function than the chance lesion of the clinical case. A great step forward in the use of ablation techniques in the search for localization of function in the brain was made by Goltz, ${ }^{30},{ }^{31},{ }^{32}$ who succeeded in mastering the technique of keeping warm-blooded animals alive for prolonged periods after drastic extirpations of large portions of their brains. His trick was to 'wash away' portions of the cerebrum instead of drastic cutting. He thus avoided severe impairment of circulation, though the method drew criticism from Hitzig ${ }^{83}$ and doubtless reduced the ability to make a precisely defined lesion. Judging by the photographs of his dogs (which he took to a professional photographic studio), he evidently did not replace the skull after removal of the underlying brain. Several of these studio portraits were found by Dr. Paul Dell in a drawer of a laboratory at Strasbourg when everything was being cleared out at the time of the Nazi invasion in the last war.

These experiments of Goltz, which he interpreted as disproving localization, have an added interest for physiologists, for one of the famous dogs was demonstrated at an international congress and then killed and had its brain removed before the audience. The brain was sent to Langleyst in Cambridge for dissection and Sherrington's first published paper (written with Langley ${ }^{35}$ ) reflects his participation in the necropsy. This was in 1884 and long before anyone suspected that the junior author was to become one of the outstanding physiologists of his time.

The physiology of the brain was now beginning to unfold and to reveal itself in dynamic terms after centuries of static representation in the two-dimensional pages of the anatomy books. To clinical observation of impairment by disease states, three experimental techniques were added: regional ablation, stimulation (both mechanical and electrical) and eventually the recording of the brain's own electricity. Mechanical and chemical irritation of the cortical surface had suggested itself to many investigators down the years, some of the attempts reaching the extremes of the bizarre. Cabanis, ${ }^{\circ}$ the celebrated physican and idéalogue, had provoked convulsive movements in muscle groups that seemed to vary with the region irritated. Earlier, Haller, ${ }^{47}$ searching for irritability, had pricked the brain and applied irritating fluids and concluded that the grey matter was insensitive to stimulation and that the white matter was the seat of sensation and the source of movement.

The Italian physiologists had been more successful. The Abbé Fontana ${ }^{25}$ and

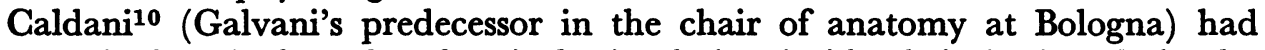
convulsed their frogs by electrical stimulation inside their brains. Rolando, following their lead, extended his experiments to pigs, goats, sheep, dogs and also to birds. The influential Magendie, however, had failed and had proclaimed the cortex electrically inexcitable, in which opinion he was backed by Flourens. In those days, before the neurone had been recognized as the unit of the nervous system, before the pyramidal fibres were known to be processes of cortical cells, 


\section{Mary A. B. Brazier}

there was no a priori reason to expect electrical stimulation of the cortical surface to have a peripheral effect, but soon an incontrovertible proof was to be given. For a new technique was to invade the field of brain localization. As everyone knows, the pioneers were the two young doctors in Berlin: Fritsch and Hitzig. ${ }^{26}$ They demonstrated that certain regions of the cortex were excitable by electricity, as evidenced by elicited movements. They did not have plain sailing, for though Ferrier ${ }^{19,}{ }^{21}$ followed up and expanded their original findings in his classic book, The Functions of the Brain, ${ }^{20}$ acceptance even then was far from general. George Henry Lewes, whose name has almost faded from scientific memory, was then a respected authority, and his Physiology of Common Life ${ }^{38}$ was the best account of the nervous system available at the time.

Lewes, better remembered for his liaison with George Eliot, wrote a pungent attack, ${ }^{39}$ both on Ferrier and on the original Fritsch-Hitzig concepts of functional localization. He deplored 'the increasingly popular but thoroughly unphysiological conception of Localization'. 'We should marvel', he wrote, 'to witness so many eminent investigators cheering each other on in the wild-goose chase of a function localized in a cerebral convolution.' Just because stimulation of a cortical area evoked a movement, that did not, in Lewes's opinion, prove it to be a motor centre. 'We do not', he wrote, 'consider the centre of laughter to be located in the sole of the foot, because tickling the sole causes laughter.'

Lewes's view was that the electrical current passed through the grey matter as through any conductor and evoked a movement by exciting the white matter. In support of this view he quoted the fact that, after removal of the cortex, electrical stimulation of the underlying white substance did indeed provoke movement, presumably via the basal ganglia.

The issue was even further obscured by a much publicized experiment of Burdon Sanderson's. The following is his own description:

If that part of the surface of the hemisphere which comprises the active spots is severed from the deeper spots by a nearly horizontal incision made with a thin-bladed knife, and the instrument is at once withdrawn without dislocation of the severed part, and the excitation of the active spots thereupon repeated, the result is the same as when the surface of the uninjured organ is acted upon.

So impressed was Burdon Sanderson by his experiments that produced movements on stimulation of the underlying white matter after removal of the cortical layers, that he became even more convinced that the motor centres lay in the basal ganglia. He may, perhaps, be regarded as a forerunner of the movement that was to develop stereotaxic methods for localization of nervous structures in the depths of the brain.

In a brain hardened in alcohol, [he wrote ${ }^{8}$ ] a needle plunged vertically, i.e. at right angles to the surface, from the active spot for retraction of the opposite ear, reaches the posterior part of the corpus striatum at a depth of from 10-12 millims. If a horizontal incision is made in the living brain, at this depth, and is met by two others, of which one is directed antero-posteriorly and the other transversely, and the part comprised within the incisions removed, a surface of brain is exposed in the deepest part of the wound which corresponds to the outer and upper part of the corpus striatum. If now the electrodes are applied to this surface, the movements ... are produced in the same way as before, but more distinctly, the active spots are quite strictly localized. . . . 


\section{The History of the Electrical Activity of the Brain}

From these facts, [he concluded], it appears that the superficial convolutions do not contain organs which are essential to the production of the combination of muscular movements now in question. They further make it probable that the doctrine hitherto accepted by physiologists, that the centres for such movements are to be found in the masses of grey matter which lie in the floor and outer wall of each lateral ventricle, is true.

Although similar results and conclusions had been reached long before him by Couty, ${ }^{15}$ comments from Burdon Sanderson were not to be shrugged off lightly for he was Jodrell Professor of Physiology at the University of London and a member of the Royal Society.

The alternative proposal was that the observed movements were secondary to sensation and that the direct effect of the stimulation was sensory rather than motor. The sensation reached the brain, an 'idea' then intervened and excited the basal ganglia to activate their motor function. This hypothesis appealed to the Victorian mind because it gave a loophole for 'free will' and 'voluntary movement'. Stimulation evoked a sensation the result of which was that one willed to move a limb. This was much more acceptable than the thought of an automatic movement resulting from excitation of certain spots in the brain.

With these busy controversies occupying the neurological world, it is not surprising that the next step should be a search for sensory centres in the brain. Yet how to find evidence of pure sensation when one's experimental animal could make no report except by a motor movement? Up to this point in the history of functional localization, the only method of attack on the difficult problem of sensory function was the type of experiment being pursued by Munk, ${ }^{48}$ namely the observation of apparent blindness or apparent deafness in an animal after regional ablations of the cortex and the assumption of sensory pathways from movements made apparently from pain. An opponent of strict localization for sensation in the brain was Wundt, ${ }^{46}$ although he agreed that some regions were dominant for certain sensations. He strove to explain transmission of sensory modalities in terms of the variety of molecular processes evoked in sensory nerves by different types of stimulation.

The advance came from physiology rather than from neurology. Whereas, at the time, localization was the ruling interest of the neurologists, the physiologists were focusing on the electrical activity of nerves. The excitement was caused by the realization that the electrical activity of the nervous system could be used as a sign of its function. In the 1840 O Du Bois-Reymond, ${ }^{16,}{ }^{17}$ the great physiologist at Berlin, had finally demonstrated unequivocally that activity in a peripheral nerve was invariably accompanied by an electrical change, a 'negative variation' in the standing potential that had been found between a cut end of the nerve and its longitudinal surface. This demonstration was the climax to a long-drawn-out struggle to confirm or deny the existence of Galvani's 'Animal Electricity'. Du Bois-Reymond did not under-estimate the importance of his demonstration. He said: 'If I do not greatly deceive myself I have succeeded in realizing in full actuality (albeit under a slightly different aspect) the hundred years' dream of physicists and physiologists, to wit, the identification of the nervous principle with electricity.'

Many workers soon confirmed that activity caused a negative variation in the 


\section{Mary A. B. Brazier}

potential difference between outside and cut surface of peripheral nerve, and in due time the idea came to some workers in distant countries, England, Russia, Poland and Austria, that the passage of sensory impulses in the brain might similarly be detectable by an electrical change.

The first to experiment with this idea was Richard Caton, a young lecturer in physiology at the Royal Infirmary in Liverpool. Following, analogously, the technique used for peripheral nerve, Caton put one recording electrode on the exposed cortex of an animal and the other on a cut surface. For stimulus he used the light from an oxy-hydrogen lamp for he had no electric light. To his delight he found the change in potential he was looking for, but in addition he found something unexpected: when he had both electrodes on the surface of the cortex, or one on the cortex and one on the skull, he found an incessant, though feeble, waxing and waning of current in the absence of all stimulation. This was the discovery of the electroencephalogram.

Many decades were to pass before the electroencephalogram was used to localize brain function, and Caton's own interest certainly turned more to the phenomenon of the major potential shift that he found on sensory stimulation. In his first brief report, ${ }^{11}$ published in the British Medical Fournal in 1875 , Caton included the following description:

The electric currents of the grey matter appear to have a relation to its function. When a part of the grey matter is in a state of functional activity, its electric current usually exhibits negative variation. For example, on the areas shown by Dr. Ferrier to be related to rotation of the head and to mastication, negative variation of the current was observed to occur whenever those two acts respectively were performed. Impressions through the senses were found to influence the currents of certain areas; e.g., the currents of that part of the rabbit's brain which Dr. Ferrier has shown to be related to movements of the eyelids, were found to be markedly influenced by stimulation of the opposite retina by light.

In his first brief report, one notices the marked impact of Ferrier's work and a tendency to expect related localizations for sensory responses and peripheral motor effects. Two years later, however, Caton reported further experiments that gave clearer results. He still proceeded to look for electrical changes in that part of the cortex stimulation of which by Ferrier had evoked movements of the head and also the area related to chewing movements. The results, as might be expected, were not too clear-cut. He reported as follows: ${ }^{12}$

An examination was made of the currents of special areas. For example, the area pointed out by Professor Ferrier as related to rotation of the head was studied in six rabbits, with a view to discover if any change in the current occurred when the animal turned the head. In two rabbits out of the six, variation of the current was observed whenever the head was turned towards the opposite side.

The masticatory area was next experimented upon in eleven rabbits and two monkeys; and in four of the former, and one of the latter, marked variation was seen whenever the animal masticated. The remaining experiments were without results, either because the animals refused to eat, or from other causes to be spoken of below.

However, Caton did make the following interesting observation:

In two rabbits, a point was discovered close to the masticatory area the current of which always showed variation when food was presented to the animal but before mastication commenced. This area was thought to be probably related to the perception of the odour of food. 


\section{The History of the Electrical Activity of the Brain}

Moving to the main goal of his experiments, namely the localization of sensory functions in the brain, Caton proceeded to examine the effect of stimulation of the several afferent modalities, tactile, auditory and visual. $\mathrm{He}$ found the following results:

A number of experiments were made to ascertain if the electric currents of any part of the hemisphere were related to common sensation in the skin. The skin was stimulated in different parts of the body by means of a gentle interrupted current. Nothing results, excepting that some evidence was obtained indicating that the currents in and about the masticatory area were influenced by stimulation of the lips and cheeks. Gentle pinching of the lips and cheeks was also seen to be invariably followed by fall in the current of the same part of the brain. This was observed in six rabbits.

Search was made to discover an area related to perceptions of sound. The electrodes were placed on various parts of the brain, and loud sounds were made close to the rabbit's ears by means of a bell, etc. No results were obtained.

A similar search was made to discover an area related to impressions on the retina. A point was found on the posterior and lateral part of the hemisphere in which, in three rabbits out of seven experimented on, variation of the current was seen to occur whenever a bright light was thrown upon the retina.

\section{Caton summed up his experiments in this report in 1877 as follows:}

The investigation thus far tends to indicate that the electrical currents of the grey matter have a relation to its function similar to that known to exist in peripheral nerves, and that the study of these currents may prove a means of throwing further light on the functions of the hemispheres.

But in the later experiments we find him moving even closer to the localization of sensation. In 1887 he visited the United States to attend the Ninth International Medical Congress in Washington, D.C., where he gave a paper entitled 'Researches on Electrical Phenomena of Cerebral Grey Matter'. 13 He reported having experimented on the brains of forty-five animals, namely cats, rabbits and monkeys, and described his operating technique, electrodes and instrumentation. His experimental design is of interest for, in spite of the necessity for making an opening in the skull, he arranged for the animal to be as unrestrained as his recording techniques would allow. He said:

Light insulated wires suspended from a support overhead connected the electrodes with the galvanometer. The animal experimented on was tethered loosely to the centre of a table a yard square, and allowed to move about, eat and drink at its pleasure.

After a description of electrical changes observed during movements of the animal, he moved on to his attempts to localize sensation. He was moderately successful with stimulation of a limb, failed to find a response to odours or to sounds, but was markedly successful when he used light as a stimulus. Of particular interest are his results with what is now called intermittent photic stimulation.

I tried the effect of alternate intervals of light and darkness on seven rabbits and four monkeys, placing the electrodes on the region stimulation of which causes movement of eyes. In three rabbits and two monkeys I found that light caused negative variation almost invariably. 


\section{Mary A. B. Brazier}

In those five experiments in which I was successful the relation between the intervals of light and darkness and the movements of the galvanometer needle was quite beyond question. If I partially shaded the animal's eye from the light, the effect on the electric current was diminished. The exact way in which the light produced its effect is not so easy to determine. It may have excited the visual centre especially, or it may have acted as a general excitant to the whole brain, or the result may possibly have been due to the heat radiated from the flame acting on the electrodes; I think one of the first two theories is more probable than the third.

The mention of a flame as the source of light used for the stimulus takes one immediately back to the gaslight era and is a reminder in this age of stroboscopes and electric flash bulbs of the primitive facilities that laboratories could offer a scientist in the last century.

The Congress at which this paper was given was held at Columbian University-now called George Washington University. At this time the Washington Monument was a very recently erected landmark, and Caton commented on this in his private diary which his daughter has generously allowed me to read. He wrote:

I stood on the sandy waste in the blazing sun in front of the vast obelisk $\ldots 555 \mathrm{ft}$. high with its sharp apex in the blue sky ... pleasing myself with the fancy that I stood in the Egyptian desert and that the wide river before me was the Nile. The obelisk is really stupendous ... . I now returned to the Columbian University building, hung up my diagrams and as soon as the Section opened, read my paper on the electrical currents of the brain. It was well received but not understood by most of the audience.

We have no photographs of Caton's recordings, for cameras had not yet become a usual part of the equipment of a biological laboratory. The first examples of photographs published from a physiological laboratory are Marey's of heart currents published in the Comptes Rendus of the Académie de Sciences in $1876 .{ }^{\circ 0} \mathrm{It}$ is perhaps rather surprising that no sketches by Caton have been found, for he was a skilled amateur artist. However, it is known that when in 189o Caton resigned from the chair of physiology at Liverpool, he gave all his material and apparatus to the department, and the cause of their subsequent disappearance has remained a mystery. Possibly some sketches of the localization of brain functions were among the lost material.

We have therefore to wait until 1890 before we see drawings depicting cortical sites for sensory function that had been found by electrical recording. In Poland a young assistant in the physiology department of the University of Jagiellonski in Krakow, Adolf Beck, not knowing of Caton's work fifteen years earlier, was searching initially for the same phenomenon, namely for electrical signs in the brain of impulses reaching it from the periphery. Like Caton before him, he succeeded, and he also found the brain-wave. His animals were mostly dogs and rabbits, and he published the protocols of all his experiments in the Polish language as the thesis for his doctorate. ${ }^{2}$

As this was a doctoral thesis, we get the experimental procedures and results reported in far more detail than in Caton's briefer publications in the medical journals. Beck, like Caton before him, found that in the dog he could evoke a potential swing as a response to light, provided at least one of his electrodes lay on the occipital cortex. In two of the experiments he described, he found a small 206 


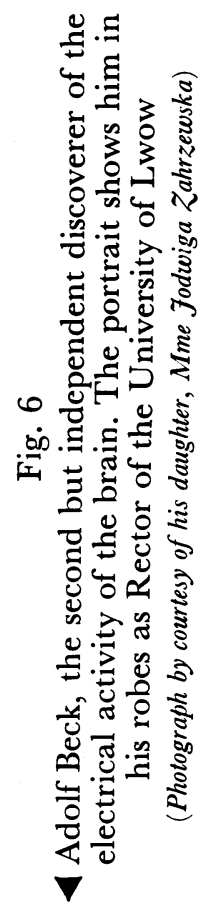

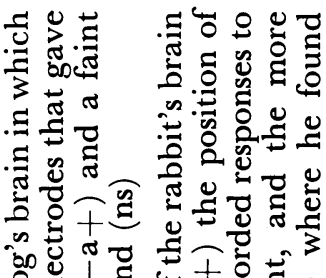

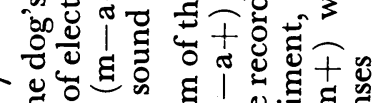

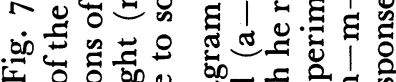

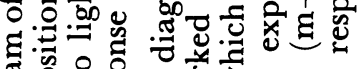

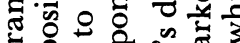

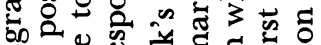

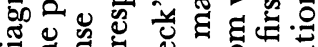

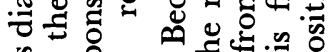
我证 部安

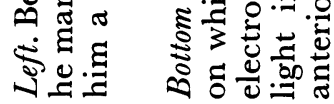
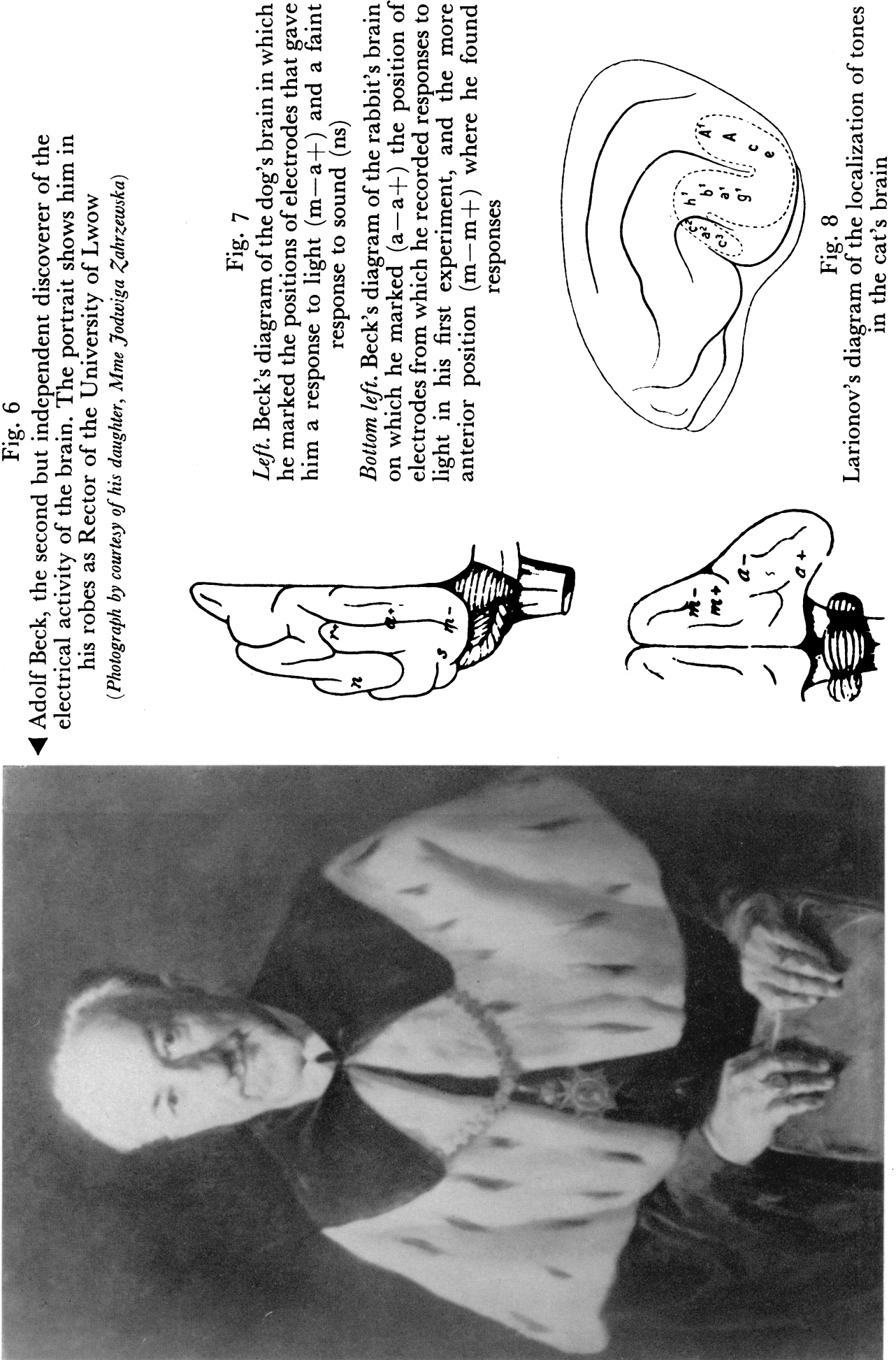


\section{The History of the Electrical Activity of the Brain}

deviation in response to a shout when one of the electrodes was on the temporal cortex.

Beck felt the challenge of his results and of his proposal that the focal shift of potential on specific sensory stimulation signified increased activity in that cortical centre. He argued that were this so, a locally produced increase of activity in that centre should produce the same potential shift. Consequently he stimulated the cortex of a dog directly with a weak induction current and obtained a marked deviation.

If my assumption concerning the relationship of the change in functional current to the origin of the active state in certain centres is correct, namely that the development of electronegativity in an area of cortex really indicates the creation of an active state in centres located there, then on direct stimulation of that site an electro-negative swing should result. . . . This was theoretical reasoning: the experiments proved that it was right. . . . Since during stimulation of the eye by light there was a positive deviation of $21 \mathrm{~mm}$, and on direct stimulation of the occipital cortex close to the negative electrode there was deviation of $80 \mathrm{~mm}$ in the same direction, does this not prove that this same cortical region went into an active state during stimulation by light? I obtained similar results on stimulating the leg and the corresponding part of the cerebral cortex, by which I mean that both gave a deviation in the direction of negativity.

Beck also at this time had no camera, but he drew many sketches to illustrate the protocols on which he recorded the movements of his galvanometer in numerical units.

Beck, again like Caton, became an extremely prominent and much revered figure, becoming eventually Rector of the Polish University of Lwow. But there the parallel ends. Caton lived to a happy old age, dying at his English home at the age of eighty-four. Beck at the age of eighty fell a victim to the German drive to exterminate the Jewish people.

Both Caton and Beck had succeeded in using electrical recording techniques for the localization of specific sensory receiving areas in the cortex. Both had observed the electroencephalographic waves superimposed on these major potential shifts. But Beck had observed yet a third phenomenon: a phenomenon that sixty years later was to be shown to be the electrical sign of the non-specific sensory system, a function of the brain undreamed of in his era.

In his very first experiment (on a rabbit) Beck found an oscillating potential difference between two electrodes placed on the occipital cortex. The fluctuations ceased when he uncovered the animal's eyes and lit a magnesium flare, and they also ceased with stimulation of the hind leg. These oscillations rode on and were additional to a direct current potential which increased with light stimulation provided he had an electrode on the occipital region. When the electrodes were placed frontally on the brain, stimulation of the hind leg also increased the standing potential and blocked the waves. A clap in the animal's ear also produced blocking but he was unsuccessful in finding an electrode position where a sound evoked a response.

Thus to Caton's discoveries Beck had added yet another-that of desynchronization of cortical activity following afferent stimulation. This phenomenon, confirmed later by many, remained an empirical observation for almost sixty 


\section{Mary A. B. Brazier}

years, until the elucidation of the desynchronizing action on cortical potentials of the ascending reticular system. Beck's own description reads as follows:

In addition to the increase or decrease in the original deviation during stimulation of the eye with light, rhythmic oscillations that have been previously described disappeared. However this phenomenon was not the consequence of light stimulation specifically for it appeared with every kind of stimulation of other afferent nerves.

In a later part of the section of his thesis in which he reviews the inferences and interpretations to be drawn from his experiments, Beck returned to the discussion of the two effects of sensory stimulation he had found in the cortex, namely the local shift in steady potential specific to the sensory system stimulated, and the non-specific blocking of the intrinsic oscillations. He wrote:

An important event which occurred in nearly all the experiments on stimulation of the cerebral cortex by any of the afferent nerves (and especially on stimulation of the sensory nerves of the skin) was the arrest of the intrinsic oscillations of the functional current. Explanation of this phenomenon would be difficult were it not accompanied by the potential shift. I would simply say that there must have been an arrest of activity at a certain point, a suppression of the intrinsic changes in the active state. In a word, it can be explained by suppression or blocking.

Perhaps one more example of localization of sensory function by electrophysiological means should be cited before we regard ourselves as having left history behind us.

Work in this field was taken up in the laboratory of Bechterev in St. Petersburg. Vladimir Michailovich Bechterev was born in 1857 and, after training at the Military Medical Academy in St. Petersburg, had studied during his twenties in the laboratories of Du Bois Reymond, of Flechsig, and of Wundt, and in the clinic of Charcot. Dedicated to what has become known as psychophysiology, he was responsible, on his return to Russia, for setting up a clinical laboratory in this subject at the University of Kazan where he was appointed as the first holder of the chair of psychiatry. In 1894 he was offered and accepted the chair of nervous and mental diseases in the Military Medical Academy at St. Petersburg, where he had once been a student, and he held this appointment until his death in 1927.

Bechterev's eminence as a clinician and experimentalist made him the outstanding figure in Russian neurology. His clinic with its laboratories became a magnet for students who were drawn to the search for a physiological basis for psychic events. One of the students, Larionov, ${ }^{36}$ was to make some of the earliest observations on the localization of tones in the auditory cortex. Vladimir Efimovich Larionov, the son of a physician, graduated from Kazan University in $188 \mathrm{I}$, and then went to St. Petersburg to the Military Academy where he gained his doctor's degree in 1898 . He worked as assistant to Bechterev, and wrote for his doctoral thesis On Cortical Centres of Hearing. His first attempts to localize tones were by extirpation experiments, and the map that he published of the points he located for the various tones of the octave in the dog's brain is of great interest for comparison with today's work in this field, accomplished by modern techniques. Impressed by demonstrations of the applicability of 208 


\section{The History of the Electrical Activity of the Brain}

electrical techniques to localization of sensory functions in the brain, for which he gave full priority to Caton, Larionov decided to adopt the galvanometric method. He used tuning-forks for his stimuli and obtained permission to use a Wiedemann-D'Arsonval galvanometer in the department of physics. His preliminary experiments were so promising that Bechterev decided to obtain one of these instruments from Paris and thus to equip his own laboratories for electrophysiological research. Bechterev was very receptive to this approach, for he himself envisaged the nerve cells of the brain as so many Leyden jars whose discharge supplied the currents recordable by these techniques.

Larionov's technique was to lead off in unipolar fashion, the reference lead being on muscle fascia. With his stigmatic electrode (made of a hair brush soaked in 0.6 per cent saline) he explored the temporal gyri for responses to tuning-forks of various tones. He reported finding 'a centre of hearing' for a low tone (tuning-fork A) in the posterior lower part of the second temporal gyrus. For tuning fork $\mathrm{A}^{\mathbf{1}}$ he found responses in the third temporal gyrus, and for $\mathrm{C}^{3}$ in the posterior half of the fourth temporal gyrus. From these experiments he concluded that the centres for hearing lay in the temporal lobes and that tones of different pitch excited topographically different areas of cortex.

Thus we see that when the century that had seen the rise of electrophysiology drew to a close, the electrical activity of the brain had yielded signs of two categories of sensory function in the brain: the potential shift that localized the specific modalities and the blocking of the electroencephalographic waves by the non-specific sensory system, the physiological mechanisms for which were to remain a mystery until unravelled by Magoun. ${ }^{41}$

But before we leave the story and recognize ourselves as belonging to the present, the brain's electrical activity was to yield a third localizing sign which in some ways is the corollary of the others. In the early days of clinical electroencephalography it was found that absence of electrical activity could be used to localize neoplasms since they contained no neuronal source of electricity, and that expanding lesions, by mechanically distorting the neurones in their neighbourhood, revealed their presence by influencing these surrounding neurones to emit abnormal discharges.

As a result of the endeavours of these pioneers, electrophysiology has emerged in today's laboratories as the pre-eminent method for the localization of brain function.

\section{REFERENCES}

I. Aubertin, E., Considerations sur les localisations cérébrales, et en particulier sur le siège de la faculté du langage articulé, Gaz. hdbd. méd. chir, 1863, 10, $3_{18}^{18}$ $348,397,455$.

2. BEGK, A., Oznaczenie lokalizacyi u mozgu $i$ rdzeniu za pomoca zjawisk elektry czynch (Thesis), Krakow, Univ. Jagiellonski, 1890.

3. Bouil aud, J. B., Traité Clinique et Physiologique de l'Encéphalite ou Inflammation du Cerveau, Paris, Baillière, 1825 .

4. BRAZIER, M. A. B., The evolution of concepts relating to the electrical activity of the nervous system, The Brain and Its Functions, ed. F. N. L. Poynter, Springfield, Thomas, Oxford, Blackwell, 1958, pp. 191-222. 


\section{Mary A. B. Brazier}

5. Brazier, M. A. B., The historical development of neurophysiology, Handbook of Neurophysiology, American Physiological Society, 1959, I, I-58.

6. - A History of the Electrical Activity of the Brain: the First Half Century of History, London, Pitman, New York, Macmillan, I96r.

7. Broca, P. P., Perte de parole, ramollissement chronique et destruction du lobe antérieur gauche du cerveau, Bull. Soc. Anthropol., Paris, I86r, 2, 235.

8. Burdon Sanderson, J. S., Note on the excitation of the surface of the cerebral hemispheres by induced currents, Proc. roy Soc., 1874, 22, 368-70.

9. Gabanis, P. J.-G., Rapports du Physique et du Moral de l'Homme, Paris, Bibliothèque Choisie, 1830 .

10. Caldani, L., Institutiones Physiologicae et Pathologicae, Leyden, Luchtmans, 1784 .

11. Caton, R., The electric currents of the brain, Brit. med. F., 1875, ii, 278.

12. - Interim report on investigation of the electric currents of the brain, Brit. med. 7., 1877, r, Suppl. 62.

13. - Researches on electrical phenomena of cerebral grey matter, Trans. Ninth Int. Med. Congr., 1887, 3, 246.

14. Ghir ac, P., De Motu Cordis Adversaria Analytica, Montpellier, 1698, 344 pp.

15. Couty, L. C., Sur la non-excitabilité de l'écorce grise du cerveau, C.R. Acad. Sci., 1879, 88, 604-7.

16. Du Bors-REYMOND, E., Untersuchungen über Thierische Elektricität, Berlin, Reimer, vol. I, 1848, vol. II, 1849 .

17. - Gesammelte Abhandlungen zur allgemeinen Muskel- und Nerve-physick, Leipzig, Veit, 1877 .

18. Duverney, J. G., Phil. Trans., 1697, I9, 225 (reported by Preston), pp. 457-67.

19. Ferrier, D., The localization of function in the brain, Proc. roy. Soc., 1873-4, 22, 229.

20. - The Functions of the Brain, vol. xv, London, Smith, Elder \& Co., 1876, p. 323 .

21. Experiments on the brain of monkeys, Phil. Trans., 1876, 165, 433.

22. Flourens, P., Recherches sur les propriétés et les fonctions du système nerveux dans les animaux vertébrés, Arch. gén. Méd., 1823, 2, 321-70.

23. - Recherches expérimentales sur les Propriétés et les Fonctions du Système Nerveux dans les Animaux Vertébrés, Paris, Crevot, 1824, 331 pp.

24. - Examen de Phrénologie, Paris, 1842, English translation by D. de L. Meigs, Phrenology Examined, Philadelphia, 1846.

25. Fontana, F., Accad. Sc. Ist, Bologna, 1757.

26. Fritsch, G. T. and Hitzig, E., Uber die elektrische Erregbarkeit des Grosshirns, Arch. Anat. Physiol. wiss. Med. Lpzg., 1870, 37, 300-33.

27. Gall, F. J., Sur les Fonctions du Cerveau et sur Celles de Chacune de ses Parties, 6 vols., Paris, $1822-5$.

28. - , and SPURZHEIM, J. G., Recherches sur le système nerveux en général, et sur celui du cerveau en particulier, Mém. Inst. Paris, 1808.

29. - Anatomie et Physiologie du Systeme Nerveux en Général et du Cerveau en Particulier, avec des Observations Intellectuelles et Morales de l'Homme et des Animaux, par la Configuration de leur Têtes, Paris, Schoell, 1810-19 (vols. I and In by Gall and Spurzheim; vols. In and Iv by Gall).

30. Goltz, F. L., Beiträge zur Lehre den Functionen der Nervenzentren des Frosches, Berlin, Hirschwald, 1869.

31. Uber die Verrichtungen des Grosshirns, gesammelte Abhandlungen, Bonn, Strauss, 1881, p. I 77. Reprinted from Arch. ges. Physiol., 1876-81, 13-26. 
32. - Der Hund ohne Grosshirn, Arch. ges. Physiol., r 892, 51, 570-6r4.

33. Hrtzig, E., Untersuchungen über das Gehirn, Arch. Anat. Physiol., 1876, pp. 692-7II.

34. LANGLEY, J. N., Report on the parts destroyed on the right side of the brain of the dog operated on by Professor Goltz, F. Physiol., 1883, 4, 286-309.

35. Langley, J. N., and Sherrington, C. S., Secondary degeneration of nerve tracts following removal of the cortex of the cerebrum in the dog, 7. Physiol, 1884, 5, 49-65.

36. LARIonov, V. E., Anatomical and other principles of science concerning the association centres of the brain, Vop. nerv.-psikh. Med. Kiev., 1903, 7, 76 (in Russian).

37. Legallois, J.J. G., Experiments on the Principle of Life and Particularly on the Principle of the Motions of the Heart, and on the Seat of this Principle, trans. by N. C. and J. C. Nancrede, Philadelphia, M. Thomas, 1813, 328 pp.

38. Lewes, G. H., The Physiology of Common Life, Blackwood, Edinburgh, 1859-60.

39. Book review of The Functions of the Brain by D. Ferrier, Nature, Lond., 1876, 25, 73-4 and 93-5.

40. MAREY, E. J., Inscription photographiques des indications de l'électromètre de Lippmann, C. R. Acad. Sci., 83, 1876, 278-80.

4I. MoruzzI, G., and Magoun, H. W., Brain stem reticular formation and activation of the EEG, EEG clin. Neurophysiol, 1949, I, 455-73.

42. Munk, H., Zur Physiologie der Grosshirnrinde, Klin. Wschr. Berlin, 1877, I4, 505.

43. Utber die Functionen der Grosshirnrinde, Berlin, Hirschwald, $188 \mathrm{I}$.

44. Perrault, G., Mémoires pour Servir d̀ l'Histoire des Animaux, Paris, Acad. Sci., $1671-6,207 \mathrm{pp}$.

45. Rolando, L., Saggio Sopra la Vera Struttura del Cervello dell'Uomo e degl'Animali e Sopra le Funzioni del Sisteme Nervoso, Sassari, 1809.

46. Wu D T, W. M., Grundzïge der physiologischen Psychologie, Leipzig, W. Engelmann, 1874 .

47. Zinn, J. G., and Haller, A., Mémoires sur les parties sensibles et irritables du corps animal, Lausanne, D'Arnay, 1760. 